\title{
Components of Responsive Health Research System in COVID-19 Crisis: Lessons Learned by Shiraz University of Medical Sciences
}

Erfan Kharazmi ( $\sim$ erfankh2001@yahoo.com )

Shiraz University of Medical Sciences School of Management and Medical Information Science https://orcid.org/0000-0002-2138-896X

\section{Sedigheh Ostovar}

Shiraz University of Medical Sciences

\section{Research}

Keywords: Research System, Health System, COVID-19

Posted Date: August 26th, 2021

DOI: https://doi.org/10.21203/rs.3.rs-816747/v1

License: (c) This work is licensed under a Creative Commons Attribution 4.0 International License.

Read Full License 


\section{Abstract}

Background: The COVID-19 pandemic has posed a major challenge to health systems all over the world. All countries have realized that they have no choice but to apply research findings to achieve real growth and development and solve their problems.

Method: A descriptive and analytical type of study was conducted with the help of experts in the field of health research. The components affecting the research system were obtained via process approach and content analysis method, and then the position of each component was identified by Mic Mac technique.

Results: Seventeen influential structural components on the health research system were identified. The leadership and management component had the most direct and indirect impact among other components. The health promotion component had a greater impact than other components.

Conclusion: All health systems need to provide adequate financial resources and manpower to provide a useful research system. Human resources are the most important inputs to such a system. Components of the research process, research Sustainability, quality, or innovation in researches can play a balancing role. The existence of appropriate infrastructures for the creation, transfer, development, and access to knowledge makes it possible to produce systematic science; it can be hoped that this science will be used in other outputs of the health research system, such as effectiveness or health promotion.

\section{Background}

The COVID-19 pandemic has posed a major challenge to health systems around the world (1). Current prevention and treatment methods that have been effective for other infectious diseases cannot be effective enough in this epidemic, and health systems are forced to discover new ways to prevent and treat the epidemic (2). One of the most obvious indicators of the growth and development of a country is its technological capabilities and scientific researches, so any action to clarify the status of research and the obstacles facing it is important (3). Conducting research studies and production of science are crucial in today's world such that the amount of articles submitted, the number of researchers, and the volume of investment in the research sector are considered as the main indicators of development in evaluating the scientific record of a country (4). All countries have realized that they have no choice but to invest and use research findings to achieve real growth and development and solve social, health, and economic problems; without research and using its results, they may not achieve sustainable development in its true sense (5). The research sector have attracted the attention of individuals in charge of health systems for various reasons. This is because the results of health research sector are very effective in securing and promoting good health for a society, neglecting of which may endanger human lives (6).

Numerous studies on health systems show that different research systems have been formed in most countries of the world (7-9); however, most of these research systems are not effective enough for health systems for various reasons, one of which is the inconsistency and divergence of researches in many research systems $(10,11)$. Another reason is the lack of a general and coordinated policy for conducting 
research in these systems $(12,13)$. In many cases, research systems may not be effective due to lack of financial resources or specialized human resources $(14,15)$.

The so-called reasons underscore the importance of having an integrated research system in all health systems in the world. In Shiraz University of Medical Sciences, after the emergence of corona crisis and due to the extensive services that this university provides in Fars Province, Iran, there was an urgent need to review the research system, and the managers and professors of this university have tried to design a suitable system through several meetings and sessions.

The present study set to design an efficient and effective system for the health system of Fars Province with the help of experts of Shiraz University of Medical Sciences and using appropriate quantitative and qualitative methods.

\section{Methods}

A descriptive and analytical study was conducted; using the opinions of experts in the field of health research, the components affecting the research system were identified, and then the position of each component in the whole system was identified by Mic Mac analysis.

Reviewing the studies, an initial list of components was prepared to identify the components, and then this list was provided to experts. In semi-structured interviews, the collective views of 30 key and expert people in the field of health research were extracted including the heads and deputies of Shiraz University of Medical Sciences, the deans and deputies of the faculties of this university, and professors of health services' management and health information management. The so-called individuals were selected based on purposive sampling method and the following criteria:

- Having at least 5 years of executive experience in health research management

- Publication of at least 10 articles in first index journals in which they were the corresponding author

- Membership in one of the research centers of Shiraz University of Medical Sciences

- Having a specialized doctoral degree in one of the specialized fields of the University of Medical Sciences

Individuals who were reluctant to participate in the study or accessing them was difficulty due to distance or busy schedule were excluded from the study and replaced by new individuals.

The final list of components of the health research system was obtained using the process approach and content analysis method. The collection of expert opinions continued until the theoretical saturation of the data was achieved and new content was not achieved. In this step, the six-step Clarke \& Braun method was used, including familiarity with the data, creating initial codes, searching for themes, forming sub-themes, defining and naming the main themes, and preparing the final list. Expert opinions were identified at three levels of conceptual, structural, and basic components. Naming structural components was done specifically based on the function of these components. Since the main purpose of this study 
was to determine the macro model of the health research system in the COVID-19 crisis, third-level (basic) components were not included in the analysis and only the first- and second-level components were used to determine the final model. Third-level components are used in the operational plans of the research system. For final review and validation, the list of components prepared was provided to two scientific experts outside the research sample, and necessary corrections were made based on their opinions.

After identifying and classifying the effective components in the health research system, Mic Mac analysis was used to determine the position, influence, effectiveness, and the stability of the designed system. The identified components were placed in the $n{ }^{\star} n$ matrix, and the variables' effectiveness or influence was scored 0 to 3 by the experts. Mick Mac matrices were formed in the following four modes, and then the matrix outputs were categorized and analyzed in the form of Mic Mac graphs and maps:

1-MDI

2-MII

3- MPDI

4- MPII

\section{Results}

In this study, 17 influential structural components in the health research system were identified. Table 1 shows the categories and titles of these components. 
Table 1

First- and second-level components of the health research system in COVID-19 crisis

\begin{tabular}{|lll|}
\hline $\begin{array}{l}\text { First-level: conceptual } \\
\text { components - title }\end{array}$ & $\begin{array}{l}\text { Second-level: structural } \\
\text { components - title }\end{array}$ & $\begin{array}{l}\text { Third-level: basic components } \\
\text { - frequency }\end{array}$ \\
\hline Enhancers & 5 \\
\hline leadership and management & 7 \\
\hline human resources & 8 \\
\hline $\begin{array}{l}\text { information systems and } \\
\text { databases }\end{array}$ & 5 \\
\hline Financing & 5 \\
\hline research process & 8 \\
\hline $\begin{array}{l}\text { knowledge management and } \\
\text { science production }\end{array}$ & 2 \\
\hline Efficiency & 7 \\
\hline Quality & 3 \\
\hline Sustainability & 4 \\
\hline Innovation & 4 \\
\hline Satisfaction & 6 \\
\hline decision making & 7 \\
\hline $\begin{array}{l}\text { responsiveness to community } \\
\text { needs }\end{array}$ & 5 \\
\hline health promotion & 4 \\
\hline Culturalization & 5 \\
\hline Equity & 5 \\
\hline Effectiveness & 5 \\
\hline Final outputs & & 5 \\
\hline
\end{tabular}

Although the third-level components were not used for modeling, for more information, the frequency of these components is listed in Table 1.

With the entry of the second-level components in Mic Mac, the position of each component in relation to other components and also their role were determined. The leadership and management component has the most direct and indirect influence among other components. The health promotion component has a greater influence than other components. 
Table 2

Influence/Dependence Matrix of health research system factors in covid 19

\begin{tabular}{|llllll|}
\hline $\mathbf{n}$ & Label & $\begin{array}{l}\text { Direct } \\
\text { Influence }\end{array}$ & $\begin{array}{l}\text { Direct } \\
\text { Dependence }\end{array}$ & $\begin{array}{l}\text { Indirect } \\
\text { Influence }\end{array}$ & $\begin{array}{l}\text { Indirect } \\
\text { Dependence }\end{array}$ \\
\hline 1 & leadership and management & 1420 & 170 & 2612 & 158 \\
\hline 2 & $\begin{array}{l}\text { information systems and } \\
\text { databases }\end{array}$ & 1306 & 397 & 2307 & 206 \\
\hline 3 & human resources & 909 & 397 & 899 & 317 \\
\hline 4 & Financing & 909 & 170 & 1861 & 101 \\
\hline 5 & $\begin{array}{l}\text { knowledge management and } \\
\text { science producing }\end{array}$ & 909 & 795 & 771 & 512 \\
\hline 6 & research process & 795 & 454 & 1394 & 281 \\
\hline 7 & Quality & 738 & 568 & 3 & 379 \\
\hline 8 & Sustainability & 681 & 568 & 0 & 399 \\
\hline 9 & Satisfaction & 625 & 795 & 1 & 591 \\
\hline 10 & decision making & 568 & 625 & 1 & 395 \\
\hline 11 & Efficiency & 511 & 738 & 0 & 457 \\
\hline 12 & Innovation & 397 & 227 & 144 & 202 \\
\hline 13 & $\begin{array}{l}\text { responsiveness to community } \\
\text { needs }\end{array}$ & 113 & 965 & 0 & 1301 \\
\hline 14 & Equity & 56 & 852 & 0 & 1268 \\
\hline 15 & Effectiveness & 56 & 909 & 0 & 1367 \\
\hline 16 & health promotion & 0 & 1022 & 0 & 0 \\
\hline 17 & Culturalization & 340 & & 1578 \\
\hline
\end{tabular}

Management and leadership components, systems and databases, financing, human resources, and research process were identified as input components in the health research system. The components of innovation, Sustainability, and culturalization are located in the position of independent components of the research system. The component of knowledge management and science production is the linkage component. Other components act as outputs for the research system. Figure 1 shows the status and position of the components relative to each other. As only one component is located in the first quarter of the map, the system under review is stable.

Drawing graphs of the influence of the components in both direct and indirect modes shows the intensity of the relationships between the studied components. In the direct mode, there are strong relationship 
between the components, while in the indirect mode, a strong relationship can only be observed between the components of management and leadership and health promotion.

\section{Discussion}

The COVID-19 pandemic has had profoundly short-term and long-term effects on all aspects of health systems (16-19). Meanwhile, research systems have also been affected by the corona epidemic $(20,21)$. In many cases, most resources and facilities of health systems have focused on the treatment sector, and other sectors, such as research, have encountered shortcomings due to the criticality of this epidemic (22, 23). However, due to the nature and scientific background of the medical profession, from the very beginning of the COVID-19 crisis, various countries have tried to fight against this epidemic by paying attention to research activities, especially in the field of vaccine production $(24,25)$. At Shiraz University of Medical Sciences, professors and administrators interested in research examined various aspects of this epidemic during various sessions and tried to keep this part of the health system active and effective by creating a conceptual model of the health research system. In this research, the so-called conceptual model has been developed using the opinions of academic experts and appropriate operational research techniques. One of the main limitations in achieving a practical model for the health research system in Shiraz University of Medical Sciences was the outbreak of Covid 19 epidemic. Due to the nature of their jobs, most of the experts did not have enough time to attend the meetings. Also, the novelty of designing the model of the research system had caused some problems.

The components identified in the health research system can take on different roles depending on their effectiveness or influence as well as their relationships with other components.

Management and leadership components, systems and databases, financing, human resources, and research process are located in the second quarter of the Mic Mac direct influences' map. These components are the inputs of the health research system and are mainly influenced from outside this system. Therefore, they can also be named as environmental variables. Some changes in these components can completely affect the system under review, and even in some cases, defects in these components can lead to a crisis in the entire health research system. Since the research process component is located near the coordinate center, it can play a regulatory role in the research system (26).

The components of innovation, Sustainability, and culturalization are located in the third quarter of the map. These variables are considered independent and have little effect on the research system according to Mic Mac maps. The Sustainability component, like the research process component, is located near the coordinate center and is therefore one of the regulators of the research system $(27,28)$.

The knowledge management and science producing component is a linkage component, i.e., it has a high influence and dependence in the research system. This component is located in the first quarter of Mic Mac coordinate and can therefore play the role of an important and intermediate goal in the research system. Studies show that in many research systems, science producing and knowledge management are the basic functions of these systems (29-31). 
The components of decision making, efficiency, satisfaction, effectiveness, equity, health promotion and responsiveness to community needs are among the outputs of the research system. However, paying attention to the position of these components shows that the dependency of components of health promotion and responsiveness to community needs is more than other components of this quarter ( 32 , 33).

Considering that some of the studied components are located near the coordinate center and play a regulatory role, the research experts developed a conceptual model of the health research system, using the outputs of Table 1 and Fig. 2. In this model, the basic concepts of the process are used. To achieve the real position of each component, direct and indirect influence numbers related to each component have been used. The model presented in Fig. 3 can provide a clearer analysis of the role and position of the components.

To create a useful research system, it is necessary to provide sufficient and appropriate financial and human resources (Fig. 3). Human resources are the most important input of such a system, and other inputs are formed based on the needs of this component $(34,35)$. As a rule, the existence of an effective database is one of the requirements of any research system, and to guide these three components, a management and leadership system is needed. The mentioned components constitute the inputs of the research system in the health system.

It is very important to pay attention to the role of regulators in this model. Components such as research process, research Sustainability, and quality or innovation in research can keep research systems balanced in the health sector and ensure the survival of such systems (36). Also, the sustainability of such a system requires culturalization in each of the health systems.

Classifying research system outputs into three categories of outputs, outcomes, and impacts can be very helpful in policy-making, planning, and evaluation of research systems. Science production and knowledge management are in fact the primary outputs of any research system (37). If research systems have appropriate infrastructures to create, transfer, develop, and access knowledge, it is possible to produce systematic science in those systems and it can be hoped that this science will be used in other outputs of the health research system such as effectiveness or health promotion (38).

\section{Conclusion}

In epidemic crises, health systems must focus their scientific efforts on identifying the causes of outbreak and prevalence and prevention and treatment methods of the epidemic. The COVID-19 pandemic has challenged health systems in recent years, and research systems must identify and discover its causes and solutions. Combining a process model with qualitative techniques such as content analysis and quantitative techniques such as Mic Mac can be beneficial in designing such systems. One of the most important inputs in such a system is the component of management and leadership, which can improve health in communities in the long run along with other components. 


\section{Abbreviations}

MDI

Matrix of Direct Influences

MII

Matrix of Indirect Influences

MPDI

Matrix of Potential Direct Influences

MPII

Matrix of Potential Indirect Influences

\section{Declarations}

Ethics approval and consent to participate:

Approval for the study was granted by the Shiraz University of medical sciences (code: 24176)

Adherence to national and international regulations:

Not applicable

Consent for publication:

Not applicable

Availability of data and materials:

Not applicable

Competing interests:

The authors declare that they have no conflict of interests.

\section{Funding:}

This study was financially supported by Mashhad University of Medical Sciences (Fund Number:24176)

\section{Authors' Contributions:}

Erfan kharazmi designed the experiments, analyzed, and wrote the manuscript. Sedigheh Ostovar gathered data and wrote the manuscript. All authors read and approved the final manuscript.

Corresponding author:

Correspondence to: Erfan Kharazmi 
Acknowledgment:

We would like to thank all participants and experts in this research.

\section{Author information:}

\section{Affiliations:}

Health Human Resources Research Center, School of Health Management and Information Sciences, Shiraz University of Medical Sciences, Shiraz, Iran

Erfan kharazmi

Shiraz University of Medical Sciences, Shiraz, Iran

Sedigheh Ostovar

\section{References}

1. -Sharma O, Sultan AA, Ding H, Triggle CR. A Review of the Progress and Challenges of Developing a Vaccine for COVID-19. Front Immunol. 2020 Oct;14:11:585354. doi:10.3389/fimmu.2020.585354.

2. -Tang YW, Schmitz JE, Persing DH, Stratton CW. Laboratory Diagnosis of COVID-19: Current Issues and Challenges. J Clin Microbiol. 2020 May 26;58(6): e00512-20. doi: 10.1128/JCM.00512-20.

3. -Ehni HJ, Wiesing U. Globalisierung in der medizinischen Forschung [Globalization in medical research]. Chirurg. 2018 Mar;89(3):178-84. 10.1007/s00104-017-0570-5. German. doi:.

4. -Farrokhyar F, Bianco D, Dao D, Ghert M, Andruszkiewicz N, Sussman J, Ginsberg JS. Impact of research investment on scientific productivity of junior researchers. Transl Behav Med. 2016 Dec;6(4):659-68. doi:10.1007/s13142-015-0361-9.

5. -Abudu R, Bouche G, Bourougaa K, Davies L, Duncan K, Estaquio C, Font AD, Hurlbert MS, Jackson P, Kroeskop-Bossenbroek L, Lewis I, Mitrou G, Mutabbir A, Pettigrew CA, Turner L, Weerman A, Wojtanik K. Trends in International Cancer Research Investment 2006-2018. JCO Glob Oncol. 2021 Apr; 7:602-610. doi: 10.1200/G0.20.00591.

6. -Bouillon R, Slordahl S, Nogueira MM, Steinhausen K, Varela-Nieto I, Pacini G, Röllinghoff M, Syka J. Public investment in biomedical research in Europe. Lancet. 2015 Oct 3;386(10001):1335. doi: 10.1016/S0140-6736(15)00326-8.

7. -Forrest CB, Chesley FD Jr, Tregear ML, Mistry KB. Development of the Learning Health System Researcher Core Competencies. Health Serv Res. 2018 Aug;53(4):2615-2632. doi: 10.1111/14756773.12751.

8. -Rasmussen TE, Kellermann AL, Rauch TM. A Primer on the Military Health System's Approach to Medical Research and Development. Acad Med. 2020 Nov;95(11):1652-7.

doi:10.1097/ACM.0000000000003186. 
9. -AlKhaldi M, Abed Y, Pfeiffer C, Haj-Yahia S, Alkaiyat A, Tanner M. Assessing policy-makers', academics' and experts' satisfaction with the performance of the Palestinian health research system: a qualitative study. Health Res Policy Syst. 2018 Jul 25;16(1):66. doi: 10.1186/s12961-018-0341-x.

10. -Savage N. Collaboration is the key to cancer research. Nature. 2018 Apr;556(7700):1-3. doi:10.1038/d41586-018-04164-7.

11. -Ziegahn L, Joosten Y, Nevarez L, Hurd T, Evans J, Dumbauld J, Eder MM. Collaboration and Context in the Design of Community-Engaged Research Training. Health Promot Pract. 2021 May;22(3):35866. doi:10.1177/1524839919894948.

12. -Guerreiro CS, Hartz Z, Sambo L, Conceição C, Dussault G, Russo G, Viveiros M, Silveira H, Pita Barros P, Ferrinho P. Política de Investigação Científica para a Saúde em Portugal: II - Factos e Sugestões [Scientific Research Policy for Health in Portugal: II - Facts and Suggestions]. Acta Med Port. 2017 Mar 31;30(3):233-242. Portuguese. doi: 10.20344/amp.8012.

13. -van Eyk H, Friel S, Sainsbury P, Boyd-Caine T, Harris P, MacDougall C, Delany-Crowe T, Musolino C, Baum F. How do advisory groups contribute to healthy public policy research? Int J Public Health. 2020 Dec;65(9):1581-1591. doi: 10.1007/s00038-020-01504-1.

14. -Stephan P. Research efficiency: Perverse incentives. Nature. 2012 Apr 4;484(7392):29-31. doi: 10.1038/484029a.

15. -Allison S, Goodall AH, Bastiampillai T. Research leadership: should clinical directors be distinguished researchers? Australas Psychiatry. 2016 Jun;24(3):249-51. doi:10.1177/1039856215612988.

16. -Ejaz H, Alsrhani A, Zafar A, Javed H, Junaid K, Abdalla AE, Abosalif KOA, Ahmed Z, Younas S. COVID-19 and comorbidities: Deleterious impact on infected patients. J Infect Public Health. 2020 Dec;13(12):1833-1839. doi: 10.1016/j.jiph.2020.07.014.

17. -Madjunkov M, Dviri M, Librach C. A comprehensive review of the impact of COVID-19 on human reproductive biology, assisted reproduction care and pregnancy: a Canadian perspective. J Ovarian Res. 2020 Nov 27;13(1):140. doi: 10.1186/s13048-020-00737-1.

18. -Cavalcanti IDL, Soares JCS. Impact of COVID-19 on cancer patients: A review. Asia Pac J Clin Oncol. 2021 Jun;17(3):186-92. doi:10.1111/ajco.13445.

19. -Tian Y, Zhou LQ. Evaluating the impact of COVID-19 on male reproduction. Reproduction. 2021 Feb;161(2):R37-44. doi:10.1530/REP-20-0523.

20. -Yazdizadeh B, Majdzadeh R, Ahmadi A, Mesgarpour B. Health research system resilience: lesson learned from the COVID-19 crisis. Health Res Policy Syst. 2020 Dec 18;18(1):136. doi: 10.1186/s12961-020-00667-w.

21. -Lu X, Xing Y, Wong GW. COVID-19: lessons to date from China. Arch Dis Child. 2020 Dec;105(12):1146-50. doi:10.1136/archdischild-2020-319261.

22. -Dawoud DM, Soliman KY. Cost-Effectiveness of Antiviral Treatments for Pandemics and Outbreaks of Respiratory Illnesses, Including COVID-19: A Systematic Review of Published Economic Evaluations. Value Health. 2020 Nov;23(11):1409-22. doi:10.1016/j.jval.2020.07.002. 
23. -Akande OW, Akande TM. COVID-19 pandemic: A global health burden. Niger Postgrad Med J. 2020 Jul-Sep;27(3):147-155. doi: 10.4103/npmj.npmj_157_20.

24. -Kamidani S, Rostad CA, Anderson EJ. COVID-19 vaccine development: a pediatric perspective. Curr Opin Pediatr. 2021 Feb 1;33(1):144-151. doi: 10.1097/MOP.0000000000000978.

25. -Guidry JPD, Laestadius LI, Vraga EK, Miller CA, Perrin PB, Burton CW, Ryan M, Fuemmeler BF, Carlyle $\mathrm{KE}$. Willingness to get the COVID-19 vaccine with and without emergency use authorization. Am J Infect Control. 2021 Feb;49(2):137-42. doi:10.1016/j.ajic.2020.11.018.

26. -Welch AJ. The researcher's reflections on the research process. Nurs Sci Q. 2004 Jul;17(3):201-7. doi:10.1177/0894318404266424.

27. -Addo-Atuah J, Senhaji-Tomza B, Ray D, Basu P, Loh FE, Owusu-Daaku F. Global health research partnerships in the context of the Sustainable Development Goals (SDGs). Res Social Adm Pharm. 2020 Nov;16(11):1614-1618. doi: 10.1016/j.sapharm.2020.08.015.

28. -Bredan A. Conducting publishable research under conditions of severely limited resources. Libyan J Med. 2020 Dec;15(1):1688126. doi:10.1080/19932820.2019.1688126.

29. -Lunden A, Teräs $M$, Kvist T, Häggman-Laitila A. A systematic review of factors influencing knowledge management and the nurse leaders' role. J Nurs Manag. 2017 Sep;25(6):407-420. doi: $10.1111 /$ jonm. 12478.

30. -Shahmoradi L, Safadari R, Jimma W. Knowledge Management Implementation and the Tools Utilized in Healthcare for Evidence-Based Decision Making: A Systematic Review. Ethiop J Health Sci. 2017 Sep;27(5):541-558. doi: 10.4314/ejhs.v27i5.13.

31. -Rocha ES, Nagliate P, Furlan CE, Rocha K Jr, Trevizan MA, Mendes IA. Knowledge management in health: a systematic literature review. Rev Lat Am Enfermagem. 2012 Mar-Apr;20(2):392-400. doi:10.1590/s0104-11692012000200024. English, Portuguese, Spanish.

32. -Roe KM. Health Promotion for These Times. Health Promot Pract. 2018 Mar;19(2):165-6. doi:10.1177/1524839918758699.

33. -Povlsen L, Borup I. Health Promotion. A developing focus area over the years. Scand J Public Health. 2015 Aug;43(16 Suppl):46-50. doi:10.1177/1403494814568595.

34. -Kanchanachitra C, Lindelow M, Johnston T, Hanvoravongchai P, Lorenzo FM, Huong NL, Wilopo SA, dela Rosa JF. Human resources for health in southeast Asia: shortages, distributional challenges, and international trade in health services. Lancet. 2011 Feb 26;377(9767):769-81. doi: 10.1016/S0140-6736(10)62035-1.

35. -Cometto G, Campbell J. Human resources for health. Lancet. 2016 Dec 17;388(10063):2993. doi: 10.1016/S0140-6736(16)32522-3.

36. -Mårtensson P, Fors U, Fröberg E, Zander U, Nilsson GH. Quality of Research Practice - An interdisciplinary face validity evaluation of a quality model. PLoS One. 2019 Feb 1;14(2):e0211636. doi: 10.1371/journal.pone.0211636.

37. -Dhombres F, Charlet J. Knowledge Representation and Management, It's Time to Integrate! Yearb Med Inform. 2017 Aug;26(1):148-151. doi: 10.15265/IY-2017-030. 
38. -Favaretti C. Knowledge management e organizzazioni sanitarie [Knowledge management and healthcare organizations]. Recenti Prog Med. 2013 Oct;104(10):532-4. Italian. doi: 10.1701/1349.14998.

\section{Figures}

Direct influence/dependence map

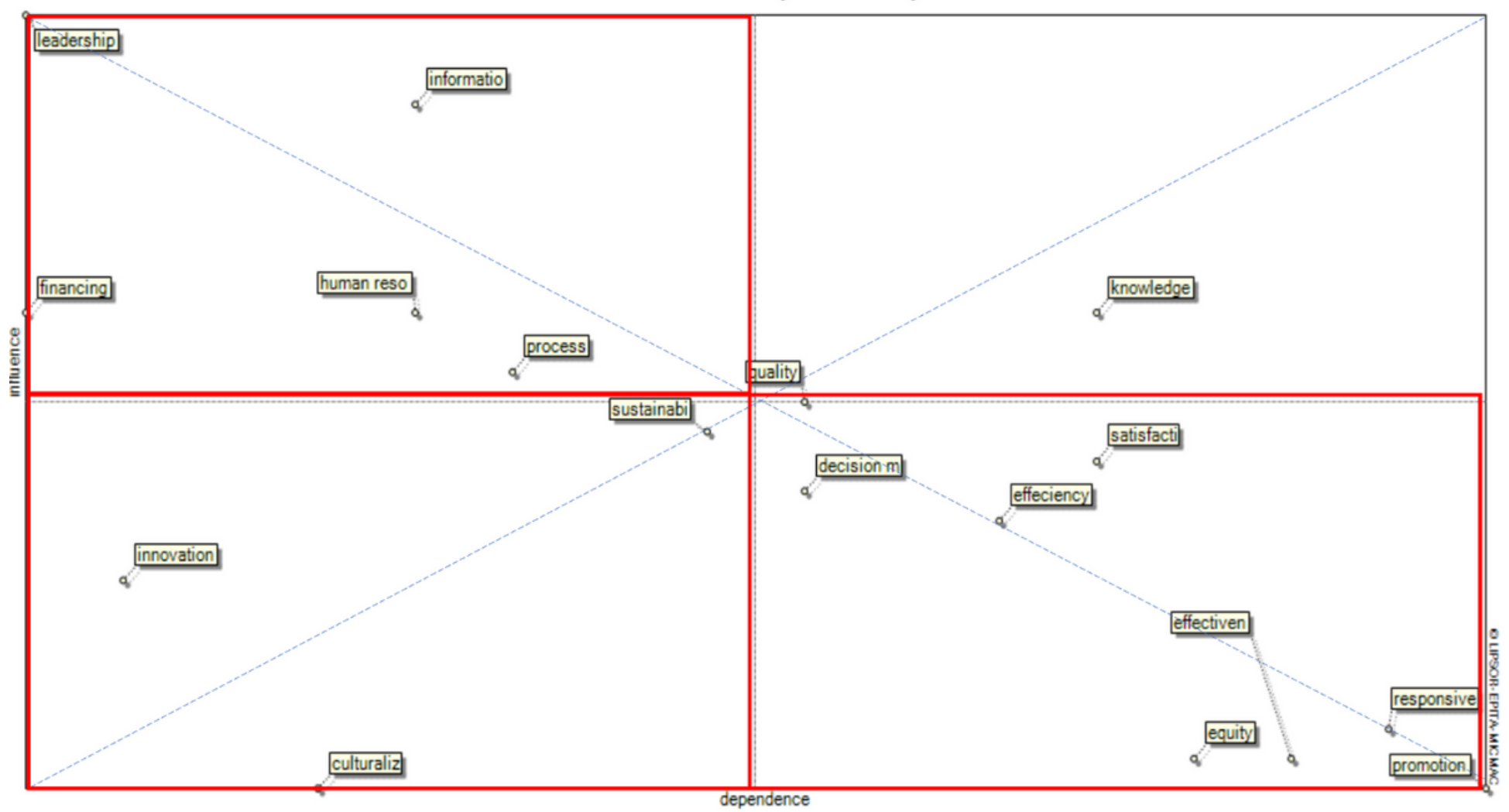

Figure 1

Map of direct and indirect influence of effective components on the health research system

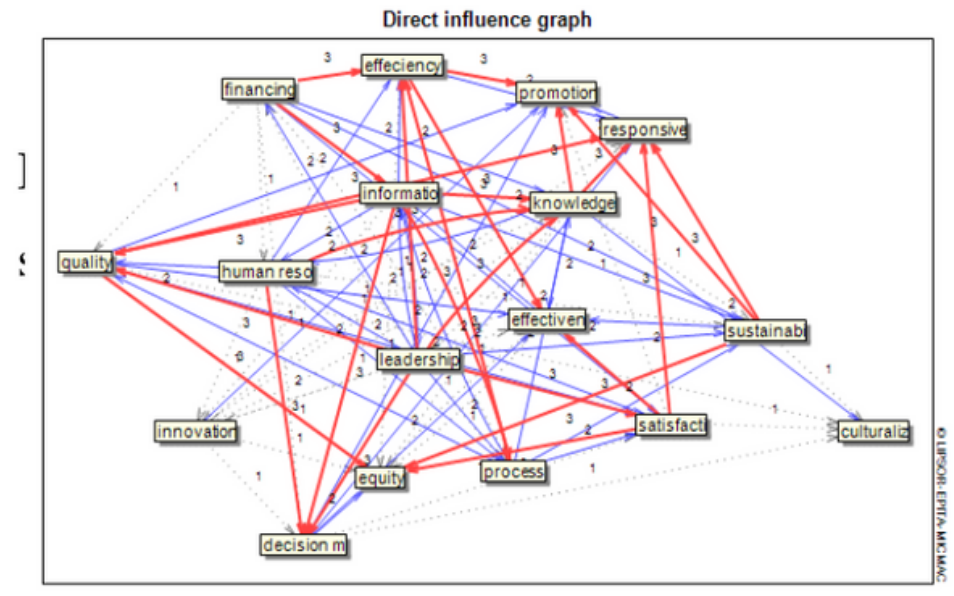

Weakest influences

- Weak influences

- Relatively strong influences

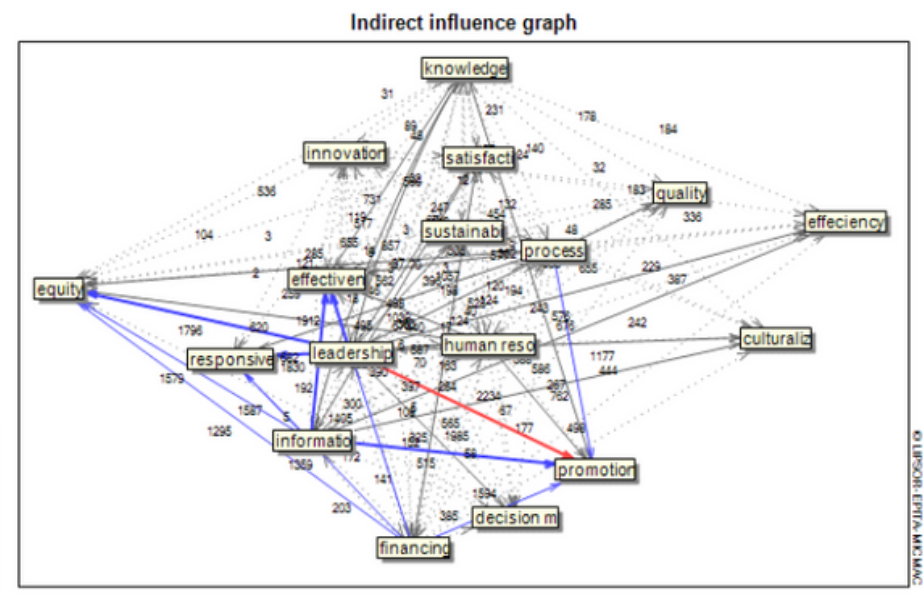

Weakest influences

Weak influences

- Relatively strong influences

- Strongestinfluences 
Figure 2

Graph of direct and indirect influence of effective components on the health research system

health research system
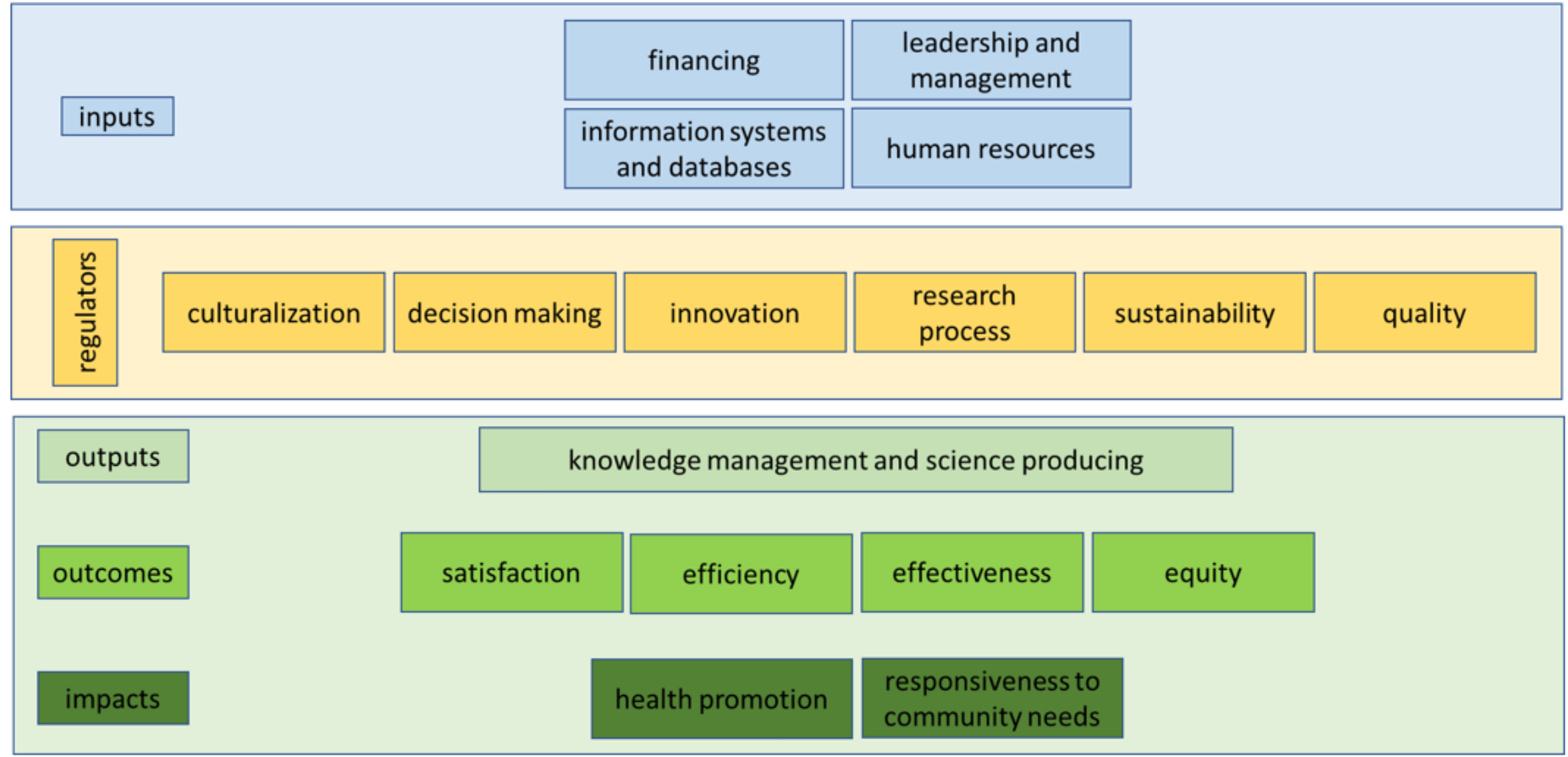

\section{Figure 3}

Conceptual model of health research system components 